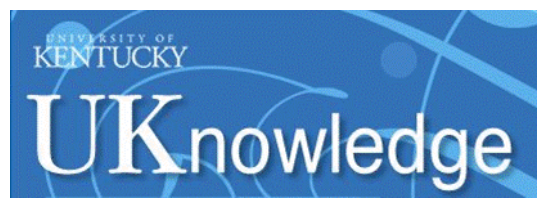

University of Kentucky

UKnowledge

\title{
Reproducibility and Discriminant Validity of the Posterior Shoulder Endurance Test in Healthy and Painful Populations
}

\author{
Neil A. Evans \\ Ohio University \\ Suzanne Konz \\ Marshall University \\ Arthur J. Nitz \\ University of Kentucky, arthur.nitz@uky.edu \\ Timothy L. Uhl \\ University of Kentucky, tluhl2@uky.edu
}

Follow this and additional works at: https://uknowledge.uky.edu/rehabsci_facpub

Part of the Rehabilitation and Therapy Commons

Right click to open a feedback form in a new tab to let us know how this document benefits you.

\section{Repository Citation}

Evans, Neil A.; Konz, Suzanne; Nitz, Arthur J.; and Uhl, Timothy L., "Reproducibility and Discriminant Validity of the Posterior Shoulder Endurance Test in Healthy and Painful Populations" (2021). Physical Therapy Faculty Publications. 117.

https://uknowledge.uky.edu/rehabsci_facpub/117

This Article is brought to you for free and open access by the Physical Therapy at UKnowledge. It has been accepted for inclusion in Physical Therapy Faculty Publications by an authorized administrator of UKnowledge. For more information, please contact UKnowledge@lsv.uky.edu. 


\section{Reproducibility and Discriminant Validity of the Posterior Shoulder Endurance}

Test in Healthy and Painful Populations

Digital Object Identifier (DOI)

https://doi.org/10.1016/j.ptsp.2020.10.014

Notes/Citation Information

Published in Physical Therapy in Sport, v. 47.

Copyright (C) 2020 Elsevier Ltd.

(c) 2020. This manuscript version is made available under the CC-BY-NC-ND 4.0 license https://creativecommons.org/licenses/by-nc-nd/4.0/. 
Reproducibility and Discriminant Validity of the Posterior Shoulder Endurance Test in Healthy and Painful Populations 
Acknowledgments: The authors would like to acknowledge the physical therapy students that assisted as research assistants during data collection as part of their capstone requirement for their Doctor of Physical Therapy degrees. We also acknowledge the for helping to provide the facilities and resources to conduct this research. 
2 Objective: This investigation measured the reproducibility and discriminant validity

3 of the Posterior Shoulder Endurance Test (PSET) on painful and non-painful

4 populations.

5 Design: Reliability and validity study

6 Setting: Laboratory setting

7 Participant: Thirty subjects (male $=11$; female $=19$ )

8 Main Outcome Measures: Time to failure (TTF) was the primary outcome measure

9 to determine reliability of the PSET. Discriminant validity identified with receiver

10 operator characteristic (ROC) curves utilized TTF separately in men and women

11 since they used different loads.

12 Results: There were 25/30 subjects (painful=12; non-painful=13) tested a second

13 time. ICC, SEM, and MDC90 ranged respectively from $0.77,13.1$ seconds, 30.6

14 seconds in the painful group to $0.85,7.3$ seconds, 17 seconds in the non-painful

15 group. The male ROC curve AUC was 0.833 with 47 seconds resulting in the best

16 combination of sensitivity $=0.833$, and specificity $=0.80$. The female ROC curve

17 AUC was 0.633 with 46 seconds resulting in the best combination of sensitivity =

$18 \quad 0.600$ and specificity $=0.889$ at 46 seconds. 
19 Conclusion: The PSET is a reliable way to measure shoulder girdle muscular

20 endurance. These data suggest that the PSET discriminates painful and non-

21 painful individuals better in men compared to women. 
22 Key Words: Shoulder endurance, test re-test reliability, discriminant validity 
Non-traumatic shoulder pain accounts for $44-65 \%$ of all musculoskeletal shoulder complaints (Lopes, Timmons, Grover, Ciconelli, \& Michener, 2015; van der Windt, Koes, de Jong, \& Bouter, 1995; Vecchio, Kavanagh, Hazleman, \& King, 1995). The mechanisms leading to non-traumatic shoulder pain are multifactorial, including kinematic alterations (Ludewig \& Reynolds, 2009; Phadke \& Ludewig, 2013), anatomic variations (Ludewig \& Reynolds, 2009), intrinsic tendon degeneration (Michener, McClure, \& Karduna, 2003), and a lack of muscular endurance (Chopp-Hurley, O'Neill, McDonald, Maciukiewicz, \& Dickerson, 2015; Chopp, O'Neill, Hurley, \& Dickerson, 2010; Lopes, et al., 2015; Michener, et al., 2003; Seitz, McClure, Finucane, Boardman, \& Michener, 2011). Therefore, clinicians are challenged to differentiate between various mechanistic contributors. Since the prevalence of non-traumatic shoulder pain is high, fully understanding the role of each potential contributing factor becomes very important for clinicians to individualize treatment.

Muscular endurance is the ability of the muscle to produce force over an extended time or perform multiple repetitions of a load (Backman, Johansson, Hager, Sjoblom, \& Henriksson, 1995). Whereas, muscular strength is the ability to produce a maximal amount of force for a short period. Therefore, the assessment methods for muscular endurance should be unique when compared to assessments of strength. Additionally, sports-related overuse shoulder injuries such as rotator cuff tendinopathy and alike caused by overhead activity, have 
45 been attributed to a lack of muscle endurance (Chopp-Hurley, et al., 2015;

Michener, et al., 2003; Sein, et al., 2010; Seitz, et al., 2011). Madsen, et al.

(Madsen, Badault, \& Nybo, 2018) found that youth badminton players with greater muscular endurance had improvements in performance. Yet, clinical tests focusing on shoulder muscular endurance are scarce (Day, Bush, Nitz, \& Uhl, 2015; Edmondston, et al., 2008; Kumta, MacDermid, Mehta, \& Stratford, 2012). Available muscular endurance measures either lack shoulder girdle specificity (Kumta, et al., 2012), or lack clinical measurement properties necessary prior to implementation (Day, et al., 2015; Edmondston, et al., 2008). Reliability and validity of clinical measures are important to assure the efficacy of the clinical tool (Impellizzeri \& Marcora, 2009).

The Scapular Endurance Test (SET) and the Posterior Shoulder Endurance Test (PSET) are two clinical tests found in the literature, which measure shoulder girdle muscular endurance (Edmondston, et al., 2008; Evans, Dressler, \& Uhl, 2018). The SET is described as having a client face a wall with the shoulders and elbows flexed to $90^{\circ}$ with a spacer positioned between the elbows (Edmondston, et al., 2008). The client holds the spacer with the elbows while maintaining a $1 \mathrm{Kg}$ load cell between his/her hands by performing shoulder external rotation (Edmondston, et al., 2008). The serratus anterior muscle is thought to be a primary muscle in the SET due to the test position, but muscle activity was not recorded (Edmondston, et al., 2008). Without knowing the extent of scapular muscle action, the SET is lacking as a clinical measure of scapular muscular 
endurance. The PSET is an isometric test performed to failure (Evans, et al., 2018). Individuals hold a standardized external load based on body weight and arm length while lying prone with the shoulder in $90^{\circ}$ of horizontal abduction and full external rotation (Chaffin DB, 1999; Evans, et al., 2018). Time to task failure (TTF) of 58.1 seconds $(95 \% \mathrm{Cl}=57.3-58.9)$ in asymptomatic females and 68.5 seconds $(95 \% \mathrm{Cl}=67.4-69.6)$ in asymptomatic males has been reported (Evans, et al., 2018). However, the TTF in painful populations has not been investigated and would provide clinicians with another test to assess muscle performance. Unlike the SET, electromyography results have been reported for the PSET. The PSET fatigues the upper, middle, and lower fibers of the trapezius, the infraspinatus, and the posterior deltoid at a similar rate between all muscles tested with one exception in males and females (Evans, et al., 2018). Day et al. (Day, et al., 2015) demonstrated muscular endurance deficits in patients with lateral epicondylalgia and those without in a variation of the PSET, suggesting the test can identify muscular performance deficits that should be addressed during rehabilitation. Based on previous findings, the PSET shows promise as a measure of shoulder muscular endurance for clinicians to address during rehabilitation. However, reliability and discriminant validity has yet to be evaluated in painful and non-painful populations for the PSET.

Therefore, the purpose of this study was to determine the inter-day test retest reliability of the PSET in both non-painful individuals and individuals with stable shoulder pain. A second purpose was to evaluate the discriminant validity 
89 of the PSET in males and females separately with and without shoulder pain.

90 Since males and females held differing amounts of external load, the discriminant

91 validity of the TTF determined from the PSET could not be directly compared

92

93 between sexes. Discriminant validity, as measured by a receiver operator characteristic (ROC) curve, will assist in establishing the diagnostic accuracy of the PSET and developing a cut-off score. We hypothesize the PSET will have moderate to excellent reliability (ICC $>0.70$ ) in painful and non-painful individuals and be able to differentiate painful individuals from non-painful individuals.

\section{METHODS}

\subsection{Evaluators}

There were two evaluators in this study. The primary investigator is a physical therapist with 16 years of experience. The primary investigator was not involved in screening the subjects to determine if they met the criteria for being in the painful group. Additionally, group classification remained blinded until after all data were collected. The primary investigator performed all PSET testing. The secondary investigator was a second-year physical therapy student that had been trained in class as well as by the primary investigator and had successfully passed skill checks for the special tests. The secondary investigator was responsible for obtaining informed consent, screening the subject for inclusion into the painful group, and any follow-up with the subject after testing. This investigator was also responsible for matching painful subjects with non-painful subjects based on age 
111 and maintaining left/right the side being tested between groups. Since painful

112 subjects always had their involved shoulder tested, the side tested on the non-

113 painful subjects were also controlled to match the number of painful subjects

114 tested. The primary investigator trained the secondary investigator on all clinical

115 testing used for determining subject inclusion prior to initiating data collection.

$116 \quad$ 2.2. Subjects

117 Subjects between 20-60 years of age, with and without non-traumatic

118 shoulder pain, were recruited to participate in the study. All subjects completed

119 university-approved informed consent, demographic information, and the

120 Pennsylvania Shoulder Score (PSS) (Leggin, et al., 2006). The secondary

121 investigator recorded weight, height, arm length, and in order to calculate standard

122 external torque applied to a subject's arm (Chaffin DB, 1999; Evans, et al., 2018).

123 The secondary investigator also performed clinical testing including Hawkins-

124 Kennedy, Empty can, Neer' Impingement sign, a painful arc between $60-120^{\circ}$, and

125 pain with external rotation manual muscle testing as described by Michener et al.

126 (Michener, Walsworth, Doukas, \& Murphy, 2009). Subjects were excluded if they

127 had uncontrolled hypertension, glaucoma, or a neurological diagnosis that would

128 impede them from performing the test.

Non-painful subjects were recruited by word-of-mouth from local orthopedic

130 physician offices and rehabilitation clinics when they were being seen for non-

131 shoulder conditions. Non-painful subjects had no history of shoulder surgery nor a

132 history of any other type of surgery within the last 6 months prior to testing. 
133 Additional inclusion for the non-painful subjects was a score $>90 / 100$ on the PSS

134 and had $\leq 2$ positive clinical tests performed by the secondary investigator.

135 Painful subjects were recruited by word-of-mouth from local orthopedic

136 physician offices and physical therapy clinics and the community-at-large.

137 Inclusion criteria for the painful group included a PSS score of $<90 / 100$ and three

138 of the following tests being positive: Hawkins-Kennedy, Empty can, Neer'

139 Impingement sign, a painful arc between $60-120^{\circ}$, and pain with external rotation

140 manual muscle testing (Michener, et al., 2009). Three of the five positive tests

141 indicated a significant area under the curve $(A \cup C)=0.79(p<0.01)$ with a positive

142 likelihood ratio (LR+) post-test probability of $54.40 \%$ (Michener, et al., 2009),

143 demonstrating a high likelihood that individuals have the condition. Subjects in the

144 painful group were excluded if found to have a positive finding for abduction drop

145 arm test, external rotation lag sign, or a positive lift-off test due to the high

146 likelihood of a rotator cuff tear (Cook \& Hegedus, 2013).

147

148

149

150

151

152 the $50^{\text {th }}$ percentile for males and females (Chaffin DB, 1999). After using

153 anthropometric data to estimate torque provided by the arm alone, an additional

154 external load was provided to the nearest $0.23 \mathrm{~kg}$ resulting in external torque for 
155 males equaling $21 \pm 2 \mathrm{Nm}$ and the external torque for females equaling $13 \pm 1$

$156 \mathrm{Nm}$. The range of weight held for the male subjects was between $1.36-2.5 \mathrm{~kg}$.

157 Female subject external loads ranged between 1.14 - and $1.59 \mathrm{~kg}$. These ranges 158 were similar to previously published values ranging from $2.05-2.5 \mathrm{~kg}$ in males and $1591.36-1.59 \mathrm{~kg}$ in females (Evans, et al., 2018).

160 Subjects performed a five-minute warm-up on an upper-body ergometer to 161 minimize the risk for muscular strain. After subjects were familiarized with the 162 testing procedures, $\mathrm{s} /$ he laid prone and held the arm at $90^{\circ}$ of horizontal abduction 163 against a stand-alone target to ensure proper form was maintained (FIGURE 1). 


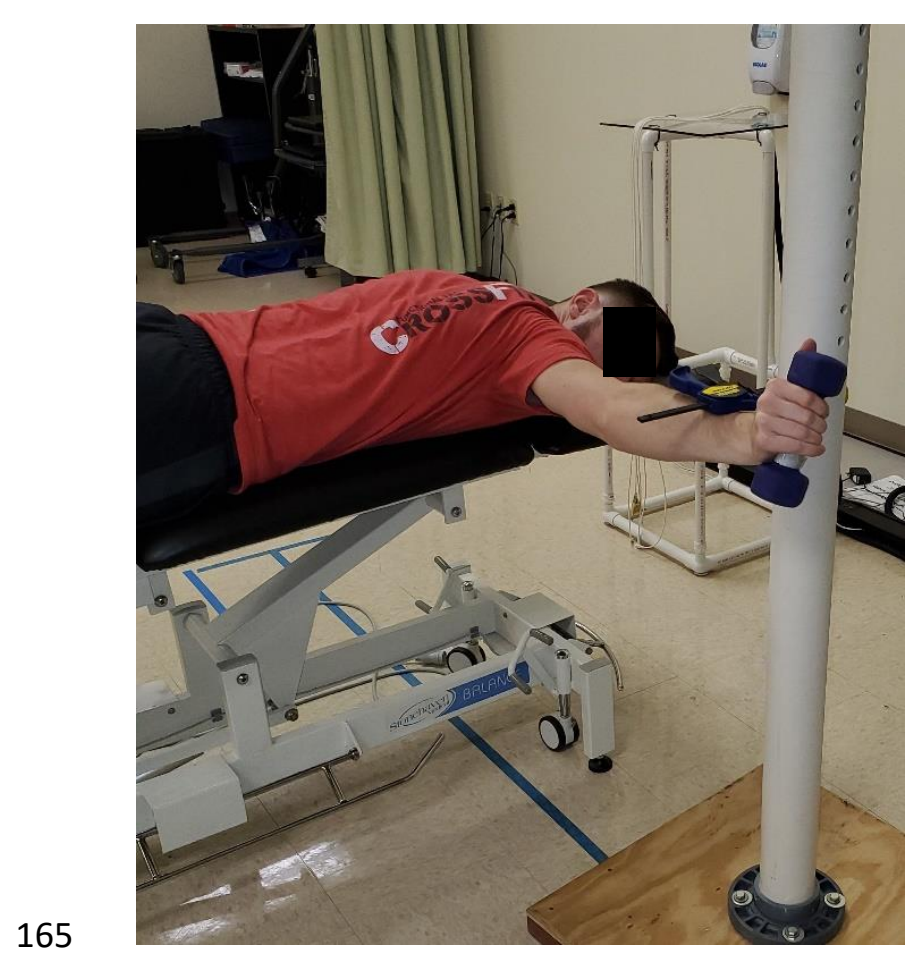

166 FIGURE 1. PSET testing position. The shoulder is at $90^{\circ}$ of abduction and $90^{\circ}$ of 167 horizontal abduction. 
169 The TTF was measured with a stopwatch and recorded as the time (seconds) in

170 which the participant initially contacted the target until the participant could no

171 longer maintain contact with the target. Verbal encouragement was provided

172 throughout the testing procedure. Failure of testing was defined as not

173 maintaining form or consistent contact with the target. Examples of test failure

174 behavior included excessive trunk rotation, inability to maintain contact with the

175 stand-alone target after verbal encouragement was provided, or self-selected

176 stoppage. Painful subjects were educated prior to testing to stop if the pain

177 became intolerable. The secondary investigator interviewed each subject after

178 testing to determine why the activity was stopped. Three painful subjects

179 discontinued the testing secondary to an increase in pain. However, the TTF for

180 those three subjects was obtained as previously described. The exact procedure

181 was reproduced 7-10 days later to assess test re-test reliability. To ensure no

182 change in symptoms between testing days, the secondary investigator asked the

183 subjects to rate any change in symptoms using the global rate of change score

184 (GROC) (Stevens, et al., 2019). The GROC is an 11-point scale measuring a

185 patient's perceived improvement or deterioration (Stevens, et al., 2019). Subjects

186 were permitted to participate in the second day of testing if they reported scores of

$187-1,0$, or +1 . Test-re-test reliability of the GROC ranges between ICC $=0.90-0.99$

188 (Stevens, et al., 2019). Three out of fifteen subjects reported a negative change in

189 the GROC score that exceeded -1 and were excluded from the reliability portion of 
190 the study. It is unknown whether the negative change in the GROC score was due

191 to the testing or was simply due to an exacerbation in their symptoms.

\section{$192 \quad$ 2.4. Statistical Analysis}

193

194

195

196

197

198

199

200

201

202

203

204

205

Prior to determining the reliability, a Shapiro-Wilk test ensured the TTF across groups was normally distributed $(p>0.05)$. TTF was used to assess the inter-day reliability of the PSET. Interclass correlation coefficients (ICC2,1) were calculated for the painful group, non-painful group, and total participants separately. ICCs were considered poor if values were $<0.5$, moderate if between 0.5 and 0.75 , good if between 0.75 and 0.90 , and excellent if $>0.90$ (Koo \& Li, 2016). ICCs were used to determine the standard error measurement $($ SEM $=$ SDpooled * $\sqrt{(1}-I C C))$, and minimal detectable change at 90\% $($ MDC90 $=(S E M$ * $\sqrt{2})^{\star} 1.65$ ) for total, painful, and non-painful groups.

Separate male and female ROC curves were calculated based on day one testing. The ROC curve coordinates are utilized to determine diagnostic validity, which provides the sensitivity and specificity of a test. The sensitivity of a test is the test's ability to identify a true positive, and specificity is the ability of the test to identify a true negative outcome. The ROC coordinates yielding the best combination of sensitivity and specificity were used to identify a cut-off score for the TTF during the PSET for males and females separately. Cut-off scores should be considered the point at which the test best discriminates individuals likely to have shoulder pain and those likely not to have shoulder pain, therefore, aiding 
211 clinicians in the interpretation of the PSET results (Carter, Pan, Rai, \& Galandiuk, 212 2016; Riddle \& Stratford, 1999). The area under the curve (AUC) of the ROC 213 curve provides the likelihood of correctly identifying the condition of true positives 214 and true negatives. Therefore, the diagnostic accuracy of the clinical test can be 215 interpreted as follows: an AUC between 0.90-1.0 = excellent, 0.80-0.90 = good, 216 0.70-0.80 $=$ moderate, $0.60-0.70=$ poor, and $<0.60=$ useless (Carter, et al., 2016;

217 Portney \& Watkins, 2009).

218

219

220

221

222

\section{RESULTS}

Thirty subjects participated in this study (female=19; male=11).

Demographics and PSS are presented in TABLE 1. As expected, painful subjects had significantly lower PSS scores than non-painful subjects $(p<0.001)$. 


\begin{tabular}{|c|c|c|c|c|}
\hline$\underline{\text { Sex }}$ & $\underline{\text { Variable }}$ & $\underline{\text { Treatment Group }}$ & Mean \pm SD & $\mathrm{p}$-value \\
\hline \multirow[t]{8}{*}{ Combined } & \multirow[t]{2}{*}{ Weight } & Non-painful & $147.6 \pm 23.9$ & \multirow{2}{*}{0.069} \\
\hline & & Painful & $178 \pm 55.7$ & \\
\hline & \multirow[t]{2}{*}{ Height } & Non-painful & $168.3 \pm 6.7$ & \multirow{2}{*}{0.185} \\
\hline & & Painful & $173 \pm 11.2$ & \\
\hline & \multirow[t]{2}{*}{ Age } & Non-painful & $32.9 \pm 12.7$ & \multirow{2}{*}{0.769} \\
\hline & & Painful & $34.3 \pm 13.0$ & \\
\hline & \multirow{2}{*}{$\begin{array}{l}\text { PSS total } \\
\text { score }\end{array}$} & Non-painful & $97.9 \pm 4.0$ & \multirow{2}{*}{$<0.001^{*}$} \\
\hline & & Painful & $72.2 \pm 13.9$ & \\
\hline \multirow[t]{8}{*}{ Males } & \multirow[t]{2}{*}{ Weight } & Non-painful & $168 \pm 20.7$ & \multirow{2}{*}{0.202} \\
\hline & & Painful & $210 \pm 66.2$ & \\
\hline & \multirow[t]{2}{*}{ Height } & Non-painful & $174.8 \pm 6.1$ & \multirow{2}{*}{$0.008^{*}$} \\
\hline & & Painful & $184.2 \pm 2.7$ & \\
\hline & \multirow[t]{2}{*}{ Age } & Non-painful & $33.4 \pm 9.3$ & \multirow{2}{*}{0.250} \\
\hline & & Painful & $41.7 \pm 12.4$ & \\
\hline & \multirow{2}{*}{$\begin{array}{l}\text { PSS total } \\
\text { score }\end{array}$} & Non-painful & $98.4 \pm 1.5$ & \multirow{2}{*}{$0.013^{*}$} \\
\hline & & Painful & $70.7 \pm 19.8$ & \\
\hline \multirow[t]{8}{*}{ Females } & \multirow[t]{2}{*}{ Weight } & Non-painful & $136.3 \pm 17.6$ & \multirow{2}{*}{0.146} \\
\hline & & Painful & $158.4 \pm 40.0$ & \\
\hline & \multirow[t]{2}{*}{ Height } & Non-painful & $164.7 \pm 3.7$ & \multirow{2}{*}{0.616} \\
\hline & & Painful & $166.3 \pm 8.5$ & \\
\hline & \multirow[t]{2}{*}{ Age } & Non-painful & $32.6 \pm 14.7$ & \multirow{2}{*}{0.656} \\
\hline & & Painful & $29.8 \pm 11.7$ & \\
\hline & \multirow{2}{*}{$\begin{array}{l}\text { PSS total } \\
\text { score }\end{array}$} & Non-painful & $97.7 \pm 4.9$ & \multirow{2}{*}{$<0.001^{*}$} \\
\hline & & Painful & $73.1 \pm 10.0$ & \\
\hline
\end{tabular}

223 TABLE 1. Patient Demographics. NOTE: Independent t-test compared across 224 groups. ${ }^{*}$ Indicates Significance $<0.05$. PSS total $=$ Pennsylvania Shoulder Score 225 total score. 
226 Intraclass correlation coefficients (ICC2,1) were assessed on 25/30

227 participants (painful $=12$, non-painful $=13$ ). One subject in each group had

228 personal conflicts, and three subjects in the painful group had a negative change

229 in GROC score that exceeded the inclusion (TABLE 2). 


\begin{tabular}{cccc} 
& Total Group & Painful Group & $\begin{array}{c}\text { Non-painful } \\
\text { Group }\end{array}$ \\
\cline { 2 - 4 } TTF Day 1 & $\begin{array}{c}51.8 \pm 25.5 \\
(\mathrm{n}=30)\end{array}$ & $\begin{array}{c}43.3 \pm 27.8 \\
(\mathrm{n}=16)\end{array}$ & $\begin{array}{c}61.5 \pm 19.3 \\
(\mathrm{n}=14)\end{array}$ \\
$\begin{array}{c}\text { TTF Day 2 } \\
\text { Mean } \pm \text { SD })\end{array}$ & $\begin{array}{c}55.5 \pm 20.8 \\
(\mathrm{n}=25)\end{array}$ & $\begin{array}{c}53.3 \pm 24.4 \\
(\mathrm{n}=12)\end{array}$ & $\begin{array}{c}57.6 \pm 17.7 \\
(\mathrm{n}=13)\end{array}$ \\
ICC2,1 & 0.80 & 0.77 & 0.85 \\
(95\%Cl) & $(0.58-0.91)$ & $(0.40-0.93)$ & $(0.58-0.95)$ \\
SEM (sec) & 10.4 & 13.1 & 7.3 \\
MDC90 (sec) & 24.4 & 30.6 & 17.0
\end{tabular}

231 TABLE 2. Intraclass correlation coefficients (ICC2,1), standard error

232 measurements (SEM), and minimal detectable changes (MDC90) of the Posterior

233 Shoulder Endurance Test in total, painful, and non-painful populations. NOTE:

234 TTF $=$ Time to Task Failure of the PSET.

235

236 
238 female (painful = 10; non-painful = 9) participants since different standardized

239 loads were used. Male ROC AUC was $0.833(\mathrm{Cl} 95 \%=0.58-1.0)$ (FIGURE 2). The

240 female ROC AUC was 0.633 (CI95\%= 0.361-0.906) (FIGURE 3). The male ROC

241 had a sensitivity $=0.833$, and specificity $=0.80$ at 47 seconds. While the female

242 ROC curve had a sensitivity $=0.600$ and specificity $=0.889$ at 46 seconds. 


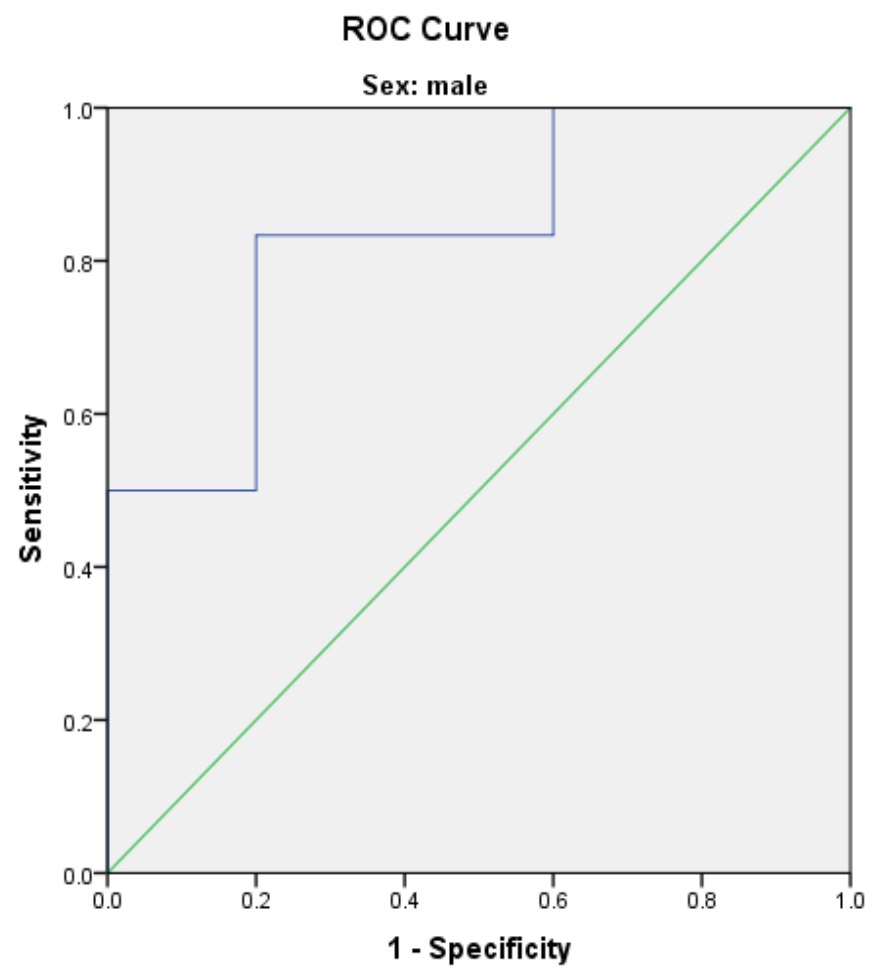

244

245 FIGURE 2. Male Participant Receiver Operating Characteristic Curve (ROC) of the 246 PSET time to task failure.

247 


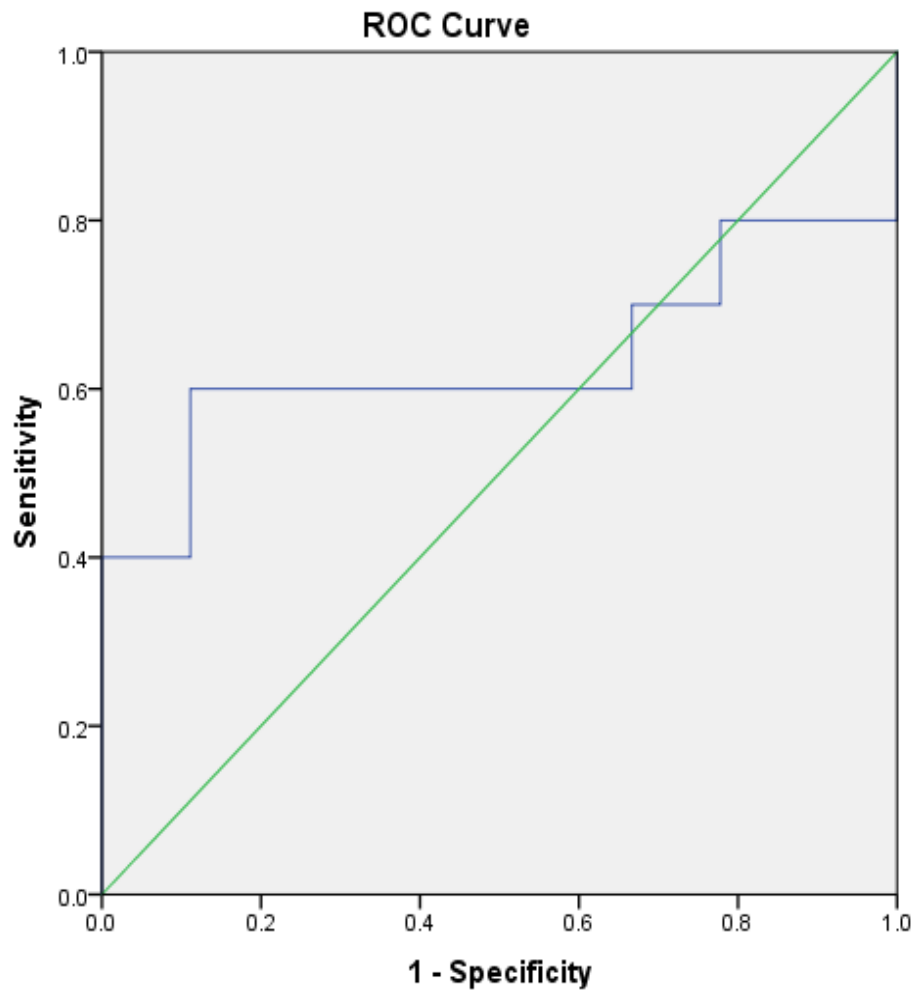

248

FIGURE 3. Female Participant Receiver Operating Characteristic Curve (ROC) of 250 the PSET time to task failure.

251 
The primary purpose of this investigation was to determine the clinical utility of the PSET by examining the inter-day reliability and discriminant validity of the measure. The data suggest the PSET has good reliability in non-painful populations $\left(\mathrm{ICC}_{2,1}=0.85\right)$, and in painful populations $\left(\mathrm{ICC}_{2,1}=0.77\right)$. Although the subjects denied changes in symptoms from day one to day two using the GROC, sub-clinical symptom changes may contribute to the reduction in reliability observed in the painful group. Since reliability is measuring the stability of the test, any symptoms must be consistent, or the test performance might change (Portney \& Watkins, 2009). Therefore, individuals with pain would be more susceptible to 263 labile symptoms, thus producing lower ICC values. However, since ICC values of $264>0.75$ have been reported as good reliability scores (Koo \& Li, 2016; Portney \& Watkins, 2009), and in the absence of other clinical measures for posterior shoulder girdle muscular endurance in subjects with and without shoulder pain, these ICCs should be considered an acceptable level of reliability. influenced by the measurement error of a test, which is directly influenced by a test ICC or stability of a test. Therefore, as the reliability decreases, the

271 responsiveness of the measure would decrease, and the ability of a test to 272 demonstrate a real change requires a greater change in the measured value.

273 Based on the current data, to be $90 \%$ confident that a true change in TTF of the 274 PSET occurred, there should be 17 seconds change in a non-painful population 
and 31 seconds change in a painful population. In a similar testing procedure, the

276

277

278

279

280

281

282

283

284

285

286

287

288

289

290

291

292

293

294

295

296

MDC90 of the PSET at $135^{\circ}$ isometric shoulder abduction was 24 seconds (Day, 2013). While Day's findings were slightly higher than this current study, the possibility of a learning effect would have likely inflated the MDC value. So, the MDC value of 17 seconds in this current study for a non-painful population is reasonable. The PSET MDC in a painful shoulder population has not been reported in previous literature. Based on the current and a previous study (Day, 2013), clinicians should consider using 30 seconds to represent a functional improvement in a painful population and 17 seconds in a non-painful population when using the PSET as a measurement tool for posterior shoulder endurance.

The scapular endurance test (SET) described by Edmondston et al.

(Edmondston, et al., 2008) reported reliability of $0.67(\mathrm{Cl} 95 \%=0.31-0.85)$ with an MDC95 of 30.1 seconds in individuals with neck pain. The reliability of the scapular endurance test in a healthy population has not been reported.

Additionally, the SET was only tested on individuals with neck pain, not shoulder pain. While the SET is performed until failure, the muscles responsible for the activity likely differ from the PSET. The muscles fatiguing during the SET have not been investigated (Edmondston, et al., 2008). However, Elkstrom et al. (Ekstrom, Donatelli, \& Soderberg, 2003) described a similar movement as demonstrating high muscle activity of serratus anterior and trapezius. Conversely, Evans et al. (Evans, et al., 2018) found that muscle activity is fatiguing in the trapezius, infraspinatus, and posterior deltoid during the PSET. So, while the results of this 
297 investigation demonstrate comparable reliability and MDC values to the SET in 298 painful populations, the PSET offers unique information since the scapular position 299 and muscles being fatigued differ.

The second purpose of this investigation was to determine if the TTF was 301 able to differentiate individuals with and without shoulder pain. Discriminant 302 validity is particularly important in a clinical setting, as clinicians are evaluating 303 patient symptoms. ROC curve plots help determine the clinical utility by plotting 304 true positive findings (Sensitivity) against false positives (1-Specificity)(Carter, et al., 2016). The current results support the PSET is good for discriminating males with and without shoulder pain $(\mathrm{AUC}=0.883)$, but poor at discriminating females with and without shoulder pain (AUC=0.633)(Carter, et al., 2016). Upon closer 308 examination of the data, there was one painful female subject that held the PSET 309 for 102 seconds, thus skewing the sensitivity and specificity of the female graph. If 310 the ROC curve were performed without the one outlier, the AUC=0.704 (CI 95\% $3110.439,0.969)$ would have improved to a moderate level. Therefore, one subject 312 made a significant difference in the ROC curve due to the small sample size.

313 Since the sample size was limited for both sexes, the authors feel further research 314 is warranted to confirm or refute these results. The ROC curve can also establish the point at which the TTF has the best combination of true positives and true negatives, known as a cut-off score (Carter, 317 et al., 2016). These data demonstrate a cut-off score that differentiated those with 318 and without shoulder pain of 46 and 47 seconds in females and males, 
respectively. The cut-off score can be interpreted as the time used to differentiate those with shoulder pain from those without shoulder pain. In a perfect test, individuals without pain should score higher than the cut-off time, and individuals with pain should score below the cut-off time. The cut-off score of 46 seconds resulted in correctly classifying $75 \%(8 / 12)$ of the non-painful and $86 \%(6 / 7)$ of the painful female participants. Therefore, the specificity is much higher compared to the sensitivity in the female population. Similarly, the male ROC curve identified a cut-off score of 47 seconds resulting in correctly classifying $80 \%(4 / 5)$ of the nonpainful and $83 \%(5 / 6)$ of the painful male participants. The combination of sensitivity (0.833) and specificity (0.80) in the male cohort produced a more meaningful combination. While these findings are novel, further research needs to be performed to improve the precision of the cut-off scores.

The PSS was collected from all participants and used to discriminate between the painful and non-painful participants (TABLE 1). However, the average PSS for the painful group was still relatively high in this sample, which indicates that they had a relatively high function and satisfaction with low pain levels. Therefore, individuals with more significant amounts of pain or acute injury may not be able to tolerate the PSET testing position. Since pain can limit performance on any functional test, a clinician should consider adding the PSET after pain severity has been mitigated. The current painful sample had an average PSS pain subscale of $20.6 \pm 3.9$ out of a score of 30 , where a score of $30 / 30$ would represent no pain. Using this sample as a guide, clinicians should be able 
341 to reasonably test patients with the PSET if they score $\geq 17 / 30$ on the PSS pain 342 subscale or a similar construct (Leggin, et al., 2006). More research is needed to 343 determine if an increase in pain and functional loss limits the subject's ability to 344 perform the PSET.

345 4.1. Limitations

346 Despite all attempts to limit the extraneous factors influencing our results, 347 this study is not without limitations. A limitation of the current investigation is the 348 sample size. A larger number of participants reduces the likelihood of over349 estimation or under-estimation of both reliability and validity measures (Portney \& 350 Watkins, 2009). The results of this investigation should be used cautiously until 351 further evidence either supports or refutes its findings. Since the results of this study are dependent on maximal effort performance 353 by subjects, the authors cannot assure that all participants were performing 354 maximally. There was an underlying assumption that all subjects would give 355 maximal effort, and clear instructions and expectations of testing were provided to 356 participants prior to testing. However, multiple factors might cause an individual to 357 stop the test including muscular fatigue, pain, or lack of motivation. A clear 358 definition of test failure was implemented to mitigate participants ceasing the 359 PSET without maximal effort. Yet, three subjects reported stopping the testing 360 secondary to pain, with the remaining participants demonstrated test failure as 361 defined a priori. A second limitation regarding effort dependent testing is whether 
362 the fatigue is of central or peripheral origin (Enoka \& Duchateau, 2008). In studies 363 using human subjects, it is difficult to control for the type of fatigue occurring.

364 Lastly, the generalizability of this study to a painful population may be 365 limited. Inclusion criteria were set to assure a strong likelihood that the painful 366 group had chronic pain that resembled tendinopathy without evidence of a tendon 367 tear (Michener, et al., 2009). Although individuals with and without shoulder pain 368 were included in this study, only sixty-nine percent of the painful subjects in the 369 current study were seeking medical care. Therefore, the results of this study may 370 not represent a population that typically seeks medical care. At this time, the 371 372 subsided.

373 374 change score of 17 and 31 seconds for non-painful and painful populations, respectively, help clinicians measure change after an intervention. More research 
384 should be performed to overcome the limitations of the current study and establish

385 a more robust diagnostic validity of the PSET. Future research should determine

386 the minimally clinically important difference (MCID) of the PSET to improve

387 responsiveness measures and if an increase in TTF of the PSET equates to an

388 improvement in painful symptoms.

389 
391 Backman, E., Johansson, V., Hager, B., Sjoblom, P., \& Henriksson, K. G. (1995).

392 Isometric muscle strength and muscular endurance in normal persons aged between 17 and 70 years. Scandinavian Journal of Rehabilitation Medicine, $27,109-117$.

Carter, J. V., Pan, J., Rai, S. N., \& Galandiuk, S. (2016). ROC-ing along: Evaluation and interpretation of receiver operating characteristic curves. Surgery, 159, 1638-1645.

Chaffin DB, A. G., Martin BJ. (1999). Occupational Biomechanics. New York, NY: John Wiley \& Sons, Inc.

Chopp-Hurley, J. N., O'Neill, J. M., McDonald, A. C., Maciukiewicz, J. M., \& Dickerson, C. R. (2015). Fatigue-induced glenohumeral and scapulothoracic kinematic variability: Implications for subacromial space reduction. Journal of Electromyography and Kinesiology.

Chopp, J. N., O'Neill, J. M., Hurley, K., \& Dickerson, C. R. (2010). Superior humeral head migration occurs after a protocol designed to fatigue the rotator cuff: a radiographic analysis. Journal of Shoulder and Elbow Surgery, 19, 1137-1144.

Cook, C., \& Hegedus, E. J. (2013). Orthopedic Physical Examination Tests: An Evidence-Based Approach (2nd ed.). Upper Saddle River, NJ: Pearson Education Inc. 
Day, J. M. (2013). Scapular Muscle Assessment in Patients with Lateral Epicondylagia. University of Kentucky, UKnowledge.

Day, J. M., Bush, H., Nitz, A. J., \& Uhl, T. L. (2015). Scapular muscle performance in individuals with lateral epicondylalgia. Journal of Orthopaedic and Sports Physical Therapy, 45, 414-424.

Edmondston, S. J., Wallumrod, M. E., Macleid, F., Kvamme, L. S., Joebges, S., \& Brabham, G. C. (2008). Reliability of isometric muscle endurance tests in subjects with postural neck pain. Journal of Manipulative and Physiological Therapeutics, 31, 348-354.

Ekstrom, R. A., Donatelli, R. A., \& Soderberg, G. L. (2003). Surface electromyographic analysis of exercises for the trapezius and serratus anterior muscles. Journal of Orthopaedic and Sports Physical Therapy, 33, 247-258.

Enoka, R. M., \& Duchateau, J. (2008). Muscle fatigue: what, why and how it influences muscle function. Journal of Physiology, 586, 11-23.

Evans, N. A., Dressler, E., \& Uhl, T. (2018). An electromyography study of muscular endurance during the posterior shoulder endurance test. Journal of Electromyography and Kinesiology, 41, 132-138.

Impellizzeri, F. M., \& Marcora, S. M. (2009). Test Validation in Sport Physiology: Lessons Learned From Clinimetrics. International Journal of Sports Physiology and Performance, 4, 269-277. 
432 Koo, T. K., \& Li, M. Y. (2016). A Guideline of Selecting and Reporting Intraclass

433

434

435

436

437

438

439

440

441

442

443

444

445

446

447

448

449

450

451 Correlation Coefficients for Reliability Research. Journal of Chiropractic Medicine, 15, 155-163.

Kumta, P., MacDermid, J. C., Mehta, S. P., \& Stratford, P. W. (2012). The FITHaNSA demonstrates reliability and convergent validity of functional performance in patients with shoulder disorders. Journal of Orthopaedic and Sports Physical Therapy, 42, 455-464.

Leggin, B. G., Michener, L. A., Shaffer, M. A., Brenneman, S. K., lannotti, J. P., \& Williams, G. R., Jr. (2006). The Penn shoulder score: reliability and validity. Journal of Orthopaedic and Sports Physical Therapy, 36, 138-151.

Lopes, A. D., Timmons, M. K., Grover, M., Ciconelli, R. M., \& Michener, L. A. (2015). Visual scapular dyskinesis: kinematics and muscle activity alterations in patients with subacromial impingement syndrome. Archives of Physical Medicine and Rehabilitation, 96, 298-306.

Ludewig, P. M., \& Reynolds, J. F. (2009). The association of scapular kinematics and glenohumeral joint pathologies. Journal of Orthopaedic and Sports Physical Therapy, 39, 90-104.

Madsen, C. M., Badault, B., \& Nybo, L. (2018). Cross-Sectional and Longitudinal Examination of Exercise Capacity in Elite Youth Badminton Players. Journal of Strength and Conditioning Research, 32, 1754-1761. 
452 Michener, L. A., McClure, P. W., \& Karduna, A. R. (2003). Anatomical and

453 biomechanical mechanisms of subacromial impingement syndrome. Clinical $454 \quad$ Biomechanics (Bristol, Avon), 18, 369-379.

455 Michener, L. A., Walsworth, M. K., Doukas, W. C., \& Murphy, K. P. (2009).

$456 \quad$ Reliability and diagnostic accuracy of 5 physical examination tests and 457 combination of tests for subacromial impingement. Archives of Physical $458 \quad$ Medicine and Rehabilitation, 90, 1898-1903.

459 Phadke, V., \& Ludewig, P. M. (2013). Study of the scapular muscle latency and 460 deactivation time in people with and without shoulder impingement. Journal 461 of Electromyography and Kinesiology, 23, 469-475.

462 Portney, L., \& Watkins, M. (2009). Foundations of Clinical Research: Application to 463 Practice (3rd ed.). Upper Saddle River, New Jersey: Pearson Prentice Hall. 464 Riddle, D. L., \& Stratford, P. W. (1999). Interpreting Validity Indexes for Diagnostic 465 466 467 Tests: An Illustration Using the Berg Balance Test. Physical Therapy, 79, 939.

Sein, M. L., Walton, J., Linklater, J., Appleyard, R., Kirkbride, B., Kuah, D., \& Murrell, G. A. (2010). Shoulder pain in elite swimmers: primarily due to swim-volume-induced supraspinatus tendinopathy. British Journal of Sports Medicine, 44, 105-113.

Seitz, A. L., McClure, P. W., Finucane, S., Boardman, N. D., 3rd, \& Michener, L. A. (2011). Mechanisms of rotator cuff tendinopathy: intrinsic, extrinsic, or both? Clinical Biomechanics (Bristol, Avon), 26, 1-12. 
474 Stevens, M. L., Lin, C. C., van der Ploeg, H. P., De Sousa, M., Castle, J.,

475 Nicholas, M. K., \& Maher, C. G. (2019). Feasibility, Validity, and

476 Responsiveness of Self-Report and Objective Measures of Physical Activity

$477 \quad$ in Patients With Chronic Pain. Pm r.

478 van der Windt, D. A., Koes, B. W., de Jong, B. A., \& Bouter, L. M. (1995). Shoulder

479 disorders in general practice: incidence, patient characteristics, and

480 management. Annals of the Rheumatic Diseases, 54, 959-964.

481 Vecchio, P. C., Kavanagh, R. T., Hazleman, B. L., \& King, R. H. (1995).

482 Community survey of shoulder disorders in the elderly to assess the natural

$483 \quad$ history and effects of treatment. Annals of the Rheumatic Diseases, 54,

$484 \quad 152-154$.

485 